\title{
RELATIONSHIP BETWEEN AEROSOL OPTICAL DEPTH AND POPULATION DENSITY IN TYPICAL AREA OF EAST CHINA
}

\author{
WANG, J. X. - WU, S. H. -ZHOU, S. L. ${ }^{*}$-TANG, J. \\ School of Geographic and Oceanographic Sciences, Nanjing University \\ Nanjing 210023, China \\ *Corresponding author \\ e-mail: zhousl@nju.edu.cn; phone: +8613805171474 \\ (Received $1^{\text {st }}$ Nov 2016; accepted $24^{\text {th }}$ Mar 2017)
}

\begin{abstract}
Air pollution is a serious environmental problem. Aerosol-which plays an important role in regional air pollution-is the main source of it. To get information of aerosol accurately and quickly, remote sensing image retrieval is an effective way. Sources of aerosols are different. Anthropogenic activity is the main factor causing thick aerosol. In that way, how to extract effective anthropogenic activity data to characterize aerosol and its influence becomes a significant scientific issue. In order to solve this problem, this paper uses HJ satellite remote sensing images and near IR-visible surface albedo correlation approach to retrieve aerosol optical depth (AOD). We also analyzed the relationship between the AOD and population density. The conclusion is as follows: (1) The spatial resolution of AOD retrieved from HJ satellite image is higher than that of the MODIS results. (2) There is a high correlation between AOD distribution and population density in the research region of east China. The correlation coefficient between population density value and the AOD is $\mathrm{R}^{2}=0.625$. (3) To most of the cities, the $\beta$ value is larger than 1 . This means that the aerosol level increases incrementally from small to larger populations in cities.
\end{abstract}

Keywords: AOD; remote sensing retrieval; population density; anthropogenic; atmospheric pollution

\section{Introduction}

Aerosol is defined as the scattered and small solid or liquid particles suspended in a gas medium in the formation of the colloidal dispersion system, also known as the gas dispersion system (Charlson et al., 1992). Aerosols plays a substantial role in global climate change and earth's atmospheric radiation balance (Rosenfeld and Woodley, 2000). Aerosols are able to interact with both incoming solar shortwave and outgoing terrestrial longwave as they scatter and absorb the short and longwave radiation as well as exert a more complex effect on climate (Charlson et al., 1992; Gunaseelan et al., 2014; Kaufman et al., 1997c; King et al., 1999; Oh et al., 2004). Aerosol is an important contributing factor to turbidity in urban areas besides having an impact on health (Che et al., 2014; Latha and Badarinath, 2005). Meanwhile, the growth of particulate emissions is expected to be greatest in developing countries, especially India and China (Wolf and Hidy, 1997).

At present, China's aerosol detection is mainly composed of ground monitoring stations. Nevertheless, because of the vast area and dispersed monitoring network, a dotted monitoring network is difficult to reflect the aerosol distribution in China comprehensively, continuously, and real-time dynamically (Ma et al., 2014). For some key monitoring areas, to provide accurate, elaborate data is difficult (Fang et al., 2013). In 
that case, using remote sensing images to retrieve and monitor aerosol is an effective way to achieve this purpose. It is a wide-coverage, real-time, and low-cost way to retrieve the aerosol optical depth (AOD) from remote sensing images (Engel-Cox et al., 2004; Kokhanovsky et al., 2007).

Nowadays, remote sensing retrieval is more and more accepted in aerosol research. There have been relatively mature and systematic studies about methods of retrieving aerosol data from satellite remote sensing images (Kaufman et al., 1997a). Thus far, a variety of retrieval methods with high precision and recognition exist (Martonchik et al., 2002). Dark pixels algorithm is a widely-used algorithm found by Yoram J. Kaufman. The albedo measured by satellite increases with the increased AOD in the circumstance that the surface albedo is low. The algorithm is sensitive to the assumed reflectance of the dense dark pixels (Kaufman and Sendra, 1988). There are three common algorithms to determine the dark pixels. Firstly, we can use the NDVI to determine the dark vegetation. The albedo of these dark pixels is taken as the surface albedo. It is a very effective algorithm to calculate the surface albedo (Kaufman and Sendra, 1988). Secondly, the albedo of 2.1 um channel is nearly not affected by AOD. As a result, we can take the albedo of 2.1um channel as the surface albedo (Eck et al., 1998). Thirdly, the albedo of 3.5 um channel is very sensitive to water, clouds, and vegetation. Meanwhile, the sizes of most aerosol are smaller than 3.5um. Thus, the albedo of $3.5 \mathrm{um}$ channel can be used to determine the dark pixels. It is usually combined with 2.1 um channel data to improve the precision (Kaufman et al., 1994; Kaufman et al., 1997b). Based on the dark pixels algorithm, many new algorithms are developing (Liang et al., 2006). Another algorithm to retrieve AOD is the structure function algorithm. It was found to solve the low precision in high-albedo area in the process of retrieval (Tanré et al., 1988; Tanre et al., 1992). This algorithm is less limited by the surface albedo, so it is mostly applied in arid and semi-arid regions. The Polarization and Directionality of the Earth's Reflectance (POLDER) is a wide field of view imaging radiometer that has provided the first global, systematic measurements of spectral, directional and polarized characteristics of the solar radiation reflected by the Earth/atmosphere system. The POLDER data can be also applied to retrieve the AOD (Deuzé et al., 2001; Deuze et al., 2003; Tanré et al., 1988; Tanre et al., 1992).

Currently, China's urbanization rate is beyond $50 \%$ and it will keep increasing in the future (Wang and Wan, 2014). The current increase of city sizes leads to less obvious but persistent increases in air pollution concentrations and related health impacts (Lianou et al., 2011; Paredes-Miranda et al., 2013). However, the relationship between urban population and quantity of aerosols in urban area gained only very limited research. The targets of this research is as follows: (1) to retrieve aerosol concentration of east China through remote sensing images, (2) to utilize the Chinese environmental satellite data to get AOD data with higher spatial resolution, (3) to analyze the correlation between population density and AOD of the region, then characterize the influence of demographic factors on AOD. 


\section{Materials and Methods}

\section{Research region}

To get the results which can be corroborated by each other, the research area should contain a variety of terrains, including plains and hills. Thus, we selected 147 cities in and around Yangtze River Delta in east China as research region, including Zhejiang, Shanghai, Jiangsu, Anhui and Jiangxi province. We selected a total of 47 counties and cities in southeastern Jiangsu, a total of 62 counties and cities in northern Zhejiang, a total of 23 counties and cities in eastern Anhui, and 7 counties and cities in parts of northeastern Jiangxi. The research region map is shown in Fig. 1.

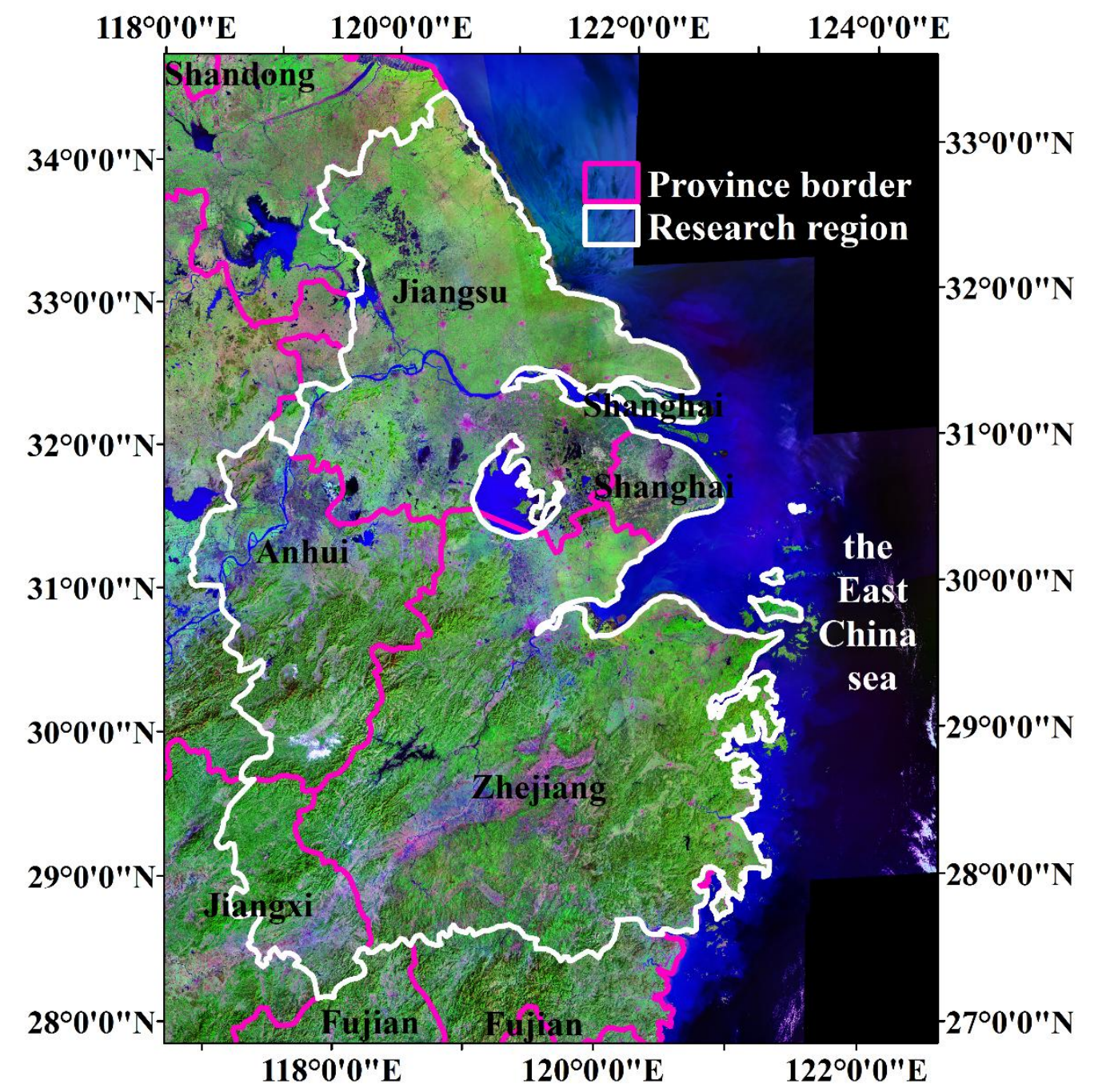

Figure 1. Remote sensing image of study area

The region belongs to the northern subtropical zone which has a temperate climate. Air is moist while four seasons are obvious there. Precipitation is relatively abundant and annual rainfall is between $1000 \mathrm{~mm}$ to $1465 \mathrm{~mm}$ with annual average temperature is 
between 15 to $17^{\circ} \mathrm{C}$. As for regional topography, western and southern areas of the region are hilly, while eastern and northern parts are flat plains. Its area is about $5 \mathrm{~km}^{2}$ and $80 \%$ of land consists of plains. The region has become one of the most developed regions in China. It has an important position in China's economic blossom. Rapid urban development and economic growth has brought prosperity to this region. Meanwhile, it also brought huge resource consumption and environmental problems. More and more industrial production and people make air pollutants as well as cause some environmental problems.

\section{Data acquisition and preprocessing}

This research chose ENVI 5.0 software in image processing and aerosol retrieval. HJ-1 satellite CCD data was acquired from China Centre for Resources Satellite Data and Application (CRESDA: http://www.cresda.com/n16/index.html). We chose a total of 18 radial images of level 2 products in Yangtze River delta region with sunny or windless weather. These images were taken from May to August in 2013. These images take Digital Number (DN) as data storage method. In that ways, before we used these images, we ought to convert DN value to real physical value through radiation calibration. Meanwhile, geometry parameters were read, such as solar zenith angle, satellite zenith angle and satellite azimuth angle data.

The resolution of HJ satellite image is $30 \mathrm{~m}$. In aerosol retrieval, retrieval results can be influenced by terrain and its shadow. Influence of such factors cause inaccurate and high manic ratio to retrieval results. The higher the resolution is, the more inaccurate the results will be. Thus, we need a resampling process for remote sensing image to enable image resolution meet the demand of aerosol retrieval precision. In our research, we diminished the length and width ten times of image measuring resolution respectively, which is 10 plus 10 resampling, to convert the image resolution into $300 \mathrm{~m} * 300 \mathrm{~m}$.

\section{Cloud remove}

A few clouds will still exist in the image despite choosing clear remote sensing images under windless weather. In the process of retrieval, if there are clouds in images, it will cause errors in results. Thus, before the aerosol retrieval we need to identify and remove clouds.

To remove clouds from the image, this research used a threshold value method. Pixel reflectivity threshold is used to determine the cloud pixel. In the use of HJ satellite remote sensing image for cloud detection research, it is concluded that the best threshold is to set reflectivity threshold to 0.2 , while near infrared and red channel ratio is set to a number between 0.9 and 1.1. In that way, our research also chose the same parameters for cloud detection. We identified the pixel where infrared and near infrared reflectance is more than 0.2 as clouds in the image, and then removed them. 


\section{Aerosol retrieval}

The basic principle of near IR-visible surface albedo correlation approach is that the surface reflectivity of the object increases with the rise of the AOD in the case of low surface reflectivity (Kaufman et al., 1997c). Assuming surface is lambert surface and atmosphere is uniform, then the earth's apparent emissivity observed by the satellite above the atmosphere can be expressed as:

$$
\rho^{*}\left(\theta_{s}, \theta_{v}, \varphi\right)=\rho_{a}\left(\theta_{s}, \theta_{v}, \varphi\right)+\frac{\rho}{1-\rho s} T\left(\theta_{s}\right) T\left(\theta_{V}\right) F_{d}\left(\theta_{s}\right) \ldots \ldots
$$

Among them $\theta_{\mathrm{s}}$ is the solar zenith angle. $\theta_{\mathrm{v}}$ is the observation direction. $\varphi$ is the angle between the scattered radiation and the sun's rays. $F_{d}\left(\theta_{s}\right)$ is the downward radiation flux when surface emissivity is zero in the normalized, equivalent to the total transmission rate down. $\mathrm{T}\left(\theta_{\mathrm{S}}\right)$ is the total transmittance upward into the direction of the satellite view. $\mathrm{S}$ is scattering ratio for the atmosphere. $\rho$ is the mean surface albedo on observation angle and incident angle (Levy et al., 2010, 2006). When apparent reflection radiation is very small or zero, the AOD can be obtained by atmospheric path radiation term $\rho_{\mathrm{a}}\left(\theta_{\mathrm{s}}, \theta_{\mathrm{v}}, \varphi\right)$. Therefore, the key problems of aerosol retrieval are removing the surface contribution $\rho$ from the apparent reflectance $\rho^{*}$ of the red and blue bands. Due to the lack of short-wave infrared wavelengths in HJ satellite image, the dark pixels can be distinguished use NDVI threshold. For the vegetation features, the larger NDVI value suggests that there is denser vegetation. In this research, we used the threshold method to extract the dark pixels in the image. The threshold is NDVI $>0.3$.

Look Up Table (LUT) is a key part in retrieval of aerosols. The $6 \mathrm{~S}$ model was commonly used to construct LUT worldwide. This research also used it. In this research, the middle latitude summer was selected for the atmospheric model, city mode was selected for the aerosol model. The AOD in lookup table ranges from 0.0001 to 1.95 , a total of eight values. In geometry settings, the solar zenith angle is set to $0-66^{\circ}$, satellite zenith angle is set to $0-39^{\circ}$, solar azimuth angle is set to $0-180^{\circ}$, and satellite azimuth angle is set to $0^{\circ}$.

To get AOD value, we combined the images after cloud removing with NDVI. The pixels whose NDVI value was higher than 0.3 were chosen. Then, the interpolation of LUT was done with the image and satellite parameters, such as angle of the sun, the solar zenith angle, satellite altitude angle, and zenith angle, given in the header file of image to get apparent reflectance of aerosol dark pixels in different AOD. After that, we compared the results with apparent reflectance of the under-retrieval images. Finally, after some processes, such as mosaic, interpolation, and clipping, we can get the AOD value of the research area. 


\section{Accuracy verification}

NASA MOD04L2 aerosol products were generated by the near IR-visible surface albedo correlation approach, using optical channel and near infrared channel data. Its resolution is $10 \mathrm{~km} * 10 \mathrm{~km}$. A large number of studies have shown that most of the MODIS aerosol products are within the error range. It can be used to test the authenticity of retrieval results of $\mathrm{HJ}$ satellite aerosols in a certain extent.

In accuracy validation process of this research, we selected the area which MOD04 aerosol product can completely cover. We compared the HJ retrieval results to the MODIS retrieval results to verify accuracy of our process.

\section{Results and Discussion}

\section{The retrieval results of $A O D$}

Using near IR-visible surface albedo correlation approach to retrieve atmospheric AOD in regions of east China in May to August 2013, the result is shown in Fig. 2. The AOD value ranges from 0.00133-1.43 in east China. Using multivariate tools in ArcGIS for calculation, we concluded that the mean and standard deviation of aerosol value in research region is 0.268 and 0.232 , respectively.

The research region was divided into Shanghai, Jiangsu, Zhejiang, Jiangxi, and Anhui by province. We calculated the mean AOD respectively. The results are shown in Table 1.

Table 1. AOD statistics displayed by province in research region

\begin{tabular}{c|c|c|c|c}
\hline Province & Minimum & Maximum & Mean & STDev \\
\hline Shanghai & 0.501 & 1.354 & 0.528 & 0.0185 \\
Jiangsu & 0.264 & 1.323 & 0.445 & 0.0895 \\
Zhejiang & 0.0281 & 1.290 & 0.237 & 0.166 \\
Anhui & 0.0397 & 1.125 & 0.295 & 0.182 \\
Jiangxi & 0.132 & 0.629 & 0.211 & 0.100 \\
\hline
\end{tabular}

As it can be seen from the table, the mean AOD in Shanghai and Jiangsu is higher, the minimum AOD of the two regions is also the highest among the five areas. The mean AOD in Zhejiang and Jiangxi is relatively low. The minimum AOD in Zhejiang and Anhui is the lowest. The maximum AOD of Shanghai, Jiangsu is highest. Coastal areas generally have higher AOD. According to Figure 2, the location of the city can be clearly distinguished. It can be concluded that the AOD of the city center area is high and that of fringe region is low. 


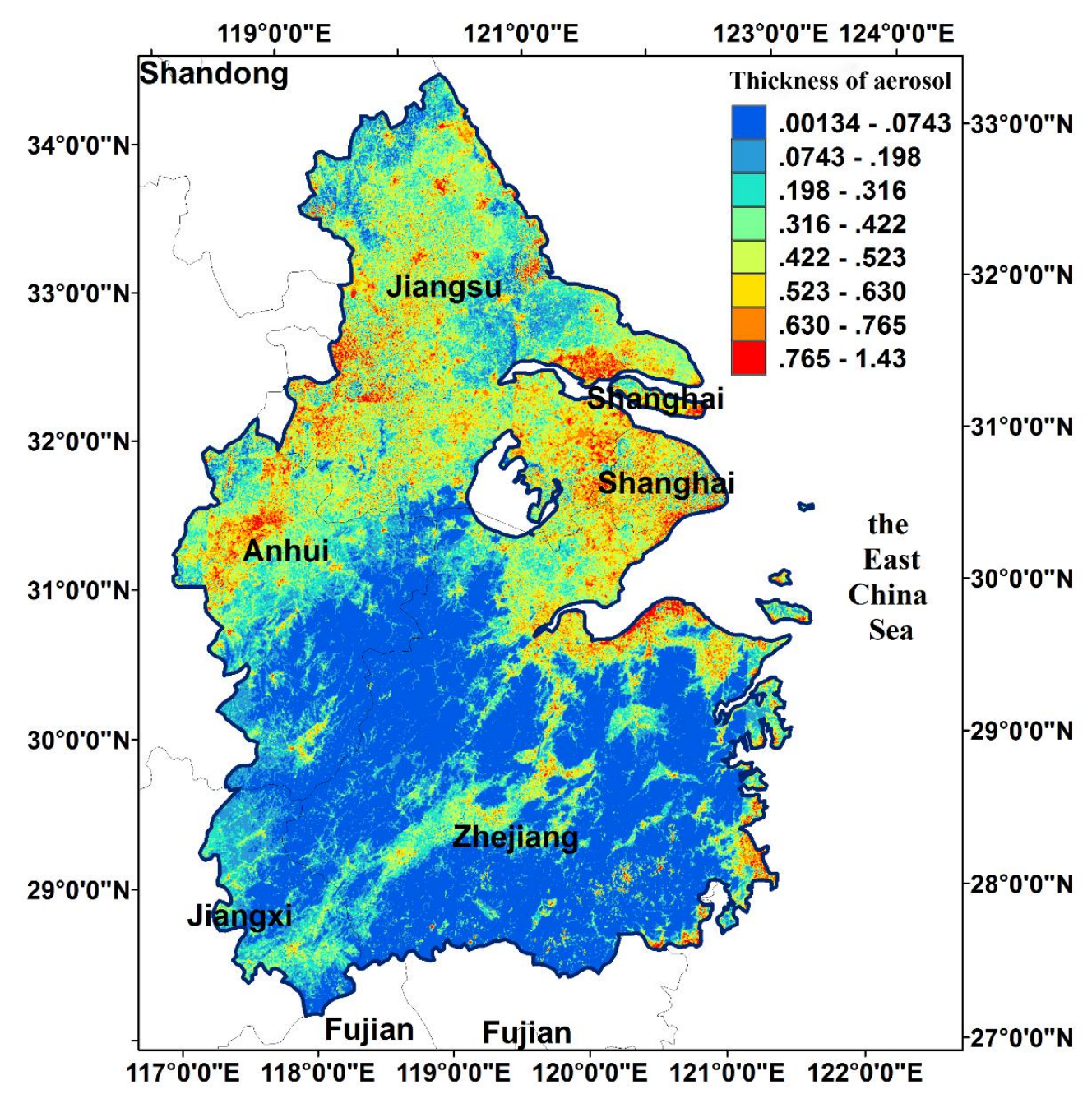

Figure 2. AOD distribution over research region

\section{Precision analysis}

The MOD04 products of June to August were retrieved from NASA's website (http://ladsweb.nascom.nasa.gov/data/search.html). The products, which can mostly cover the research region, were chosen. MCTK tool was used to extract the data of aerosol. The extraction results are shown (Fig. 3).

74 counties which MOD04 can completely cover were selected in the research region. The mean AOD was calculated in scope of each county or city on both MOD04 products and HJ retrieval. The scatterplot was drawn per statistics of average AOD and the trend line was fit. Results are shown in Fig. 4.

It can be drawn that the correlation coefficient between retrieval results and MODIS04 aerosol products are high. $\mathrm{R}^{2}$ is 0.718 while $\mathrm{F}$ value is 187.1 which is greater than the $\mathrm{F}_{0.05}(1,72)$. It indicates that fitting coefficient meets confidence level. The AOD results of two kinds of sensor data are shown in Table 2. 


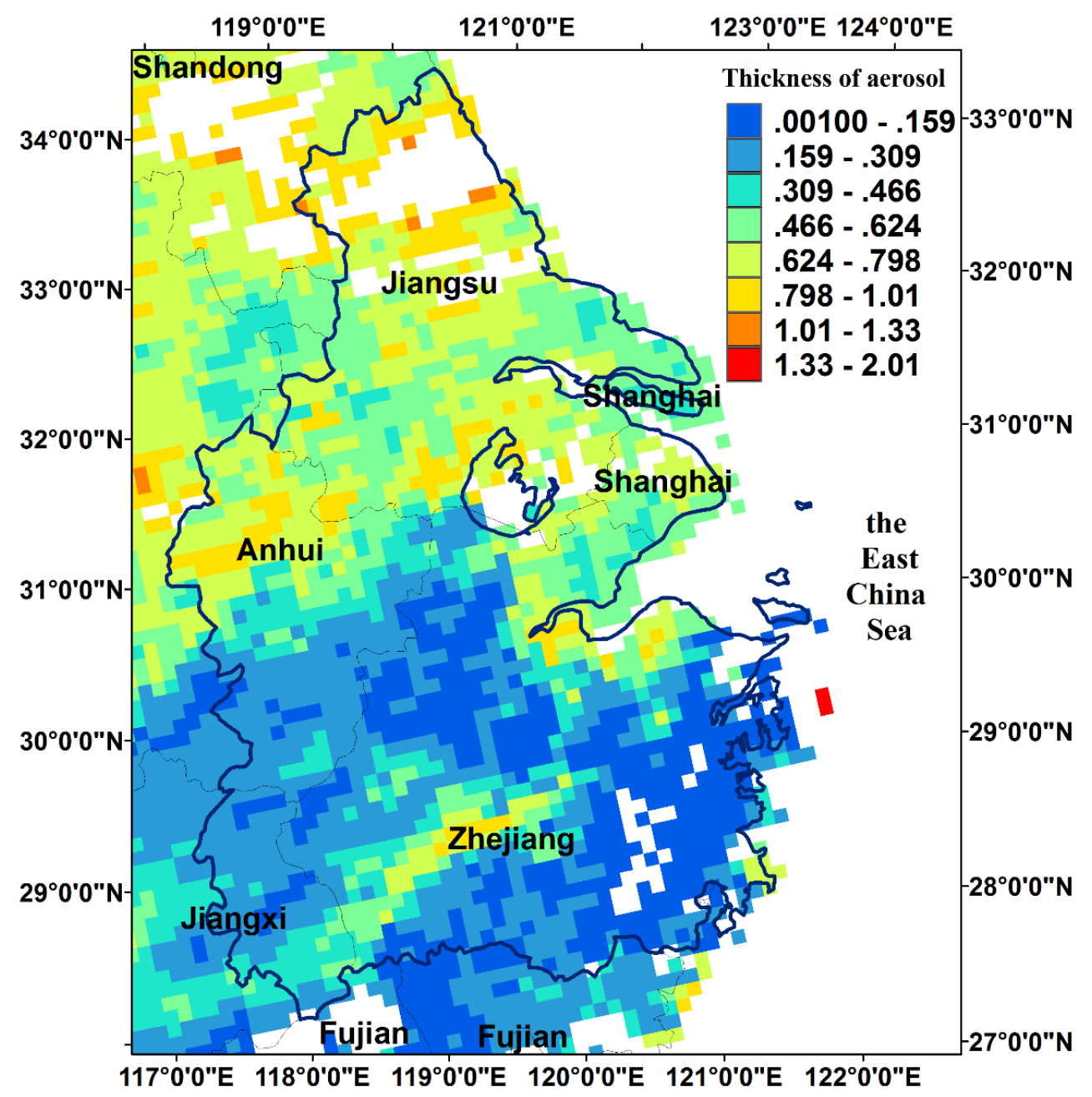

Figure 3. $A O D$ result of $M O D 04$

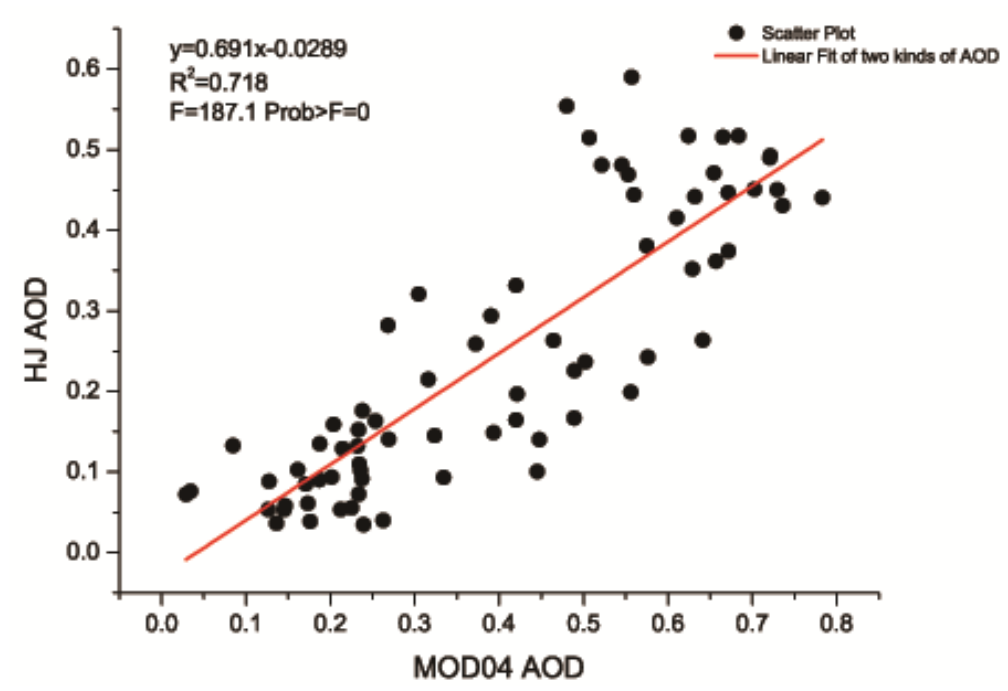

Figure 4. Scatter diagram of $A O D$ from $M O D O 4$ and $H J$

APPLIED ECOLOGY AND ENVIRONMENTAL RESEARCH 15(3): 1041-1056. http://www.aloki.hu • ISSN 15891623 (Print) • ISSN 17850037 (Online) DOI: http://dx.doi.org/10.15666/aeer/1503_10411056 (c) 2017, ALÖKI Kft., Budapest, Hungary 
Table 2. AOD statistics of HJ and MODO4

\begin{tabular}{c|c|c|c|c|c}
\hline Satellite & Mean & Minimum & Maximum & STDev & AE \\
\hline HJ & 0.397 & 0.0289 & 0.783 & 0.207 & 0.183 \\
AOD & 0.245 & 0.0349 & 0.590 & 0.168 & 0.148 \\
\hline
\end{tabular}

Comparing two sets of data, the mean value of $\mathrm{HJ}$ retrieval is 0.397 with a range of 0.289 to 0.783 . The mean value of MODIS04 is 0.245 with a range of 0.349 to 0.590 . Standard deviation of HJ is slightly superior to that of MODIS04. The absolute error of HJ retrieval is on high side. Also, the HJ retrieval aerosol value was slightly undervalued. Overall, it still reflects a higher correlation, which indicates that the retrieval precision is reliable.

\section{Comparison with $A O D$ and population}

The world population density figure of 2010 was retrieved from the Center for International Earth Science Information Network (CIESIN: http://www.ciesin.org/). Population density distribution figure in the research region was retrieved after interpolation and clipping the origin figure. It is shown in Fig. 5.

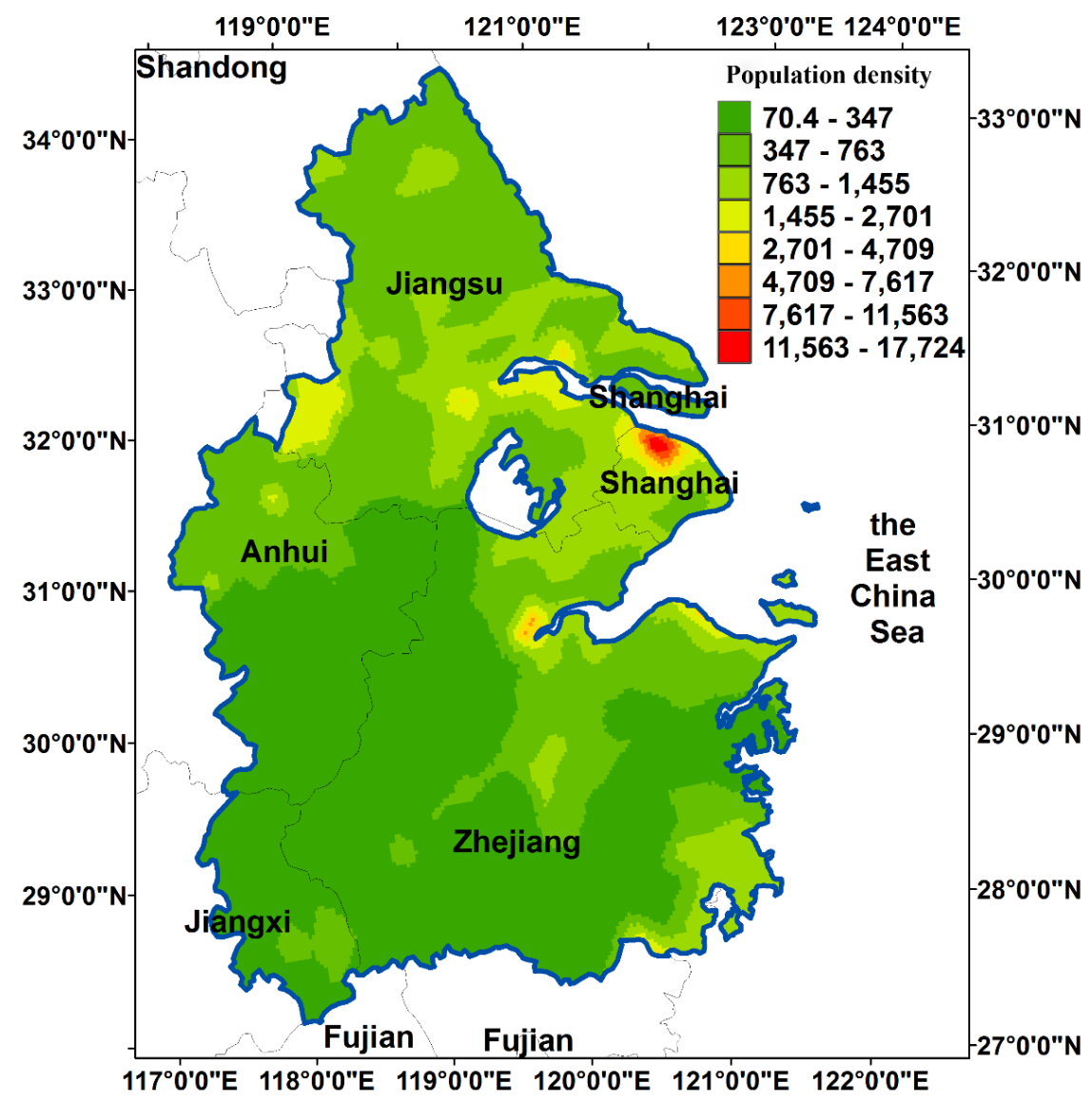

Figure 5. Population density in study zone 
Fig. 6 is contour figure converted from population density superimposed on the results of AOD.

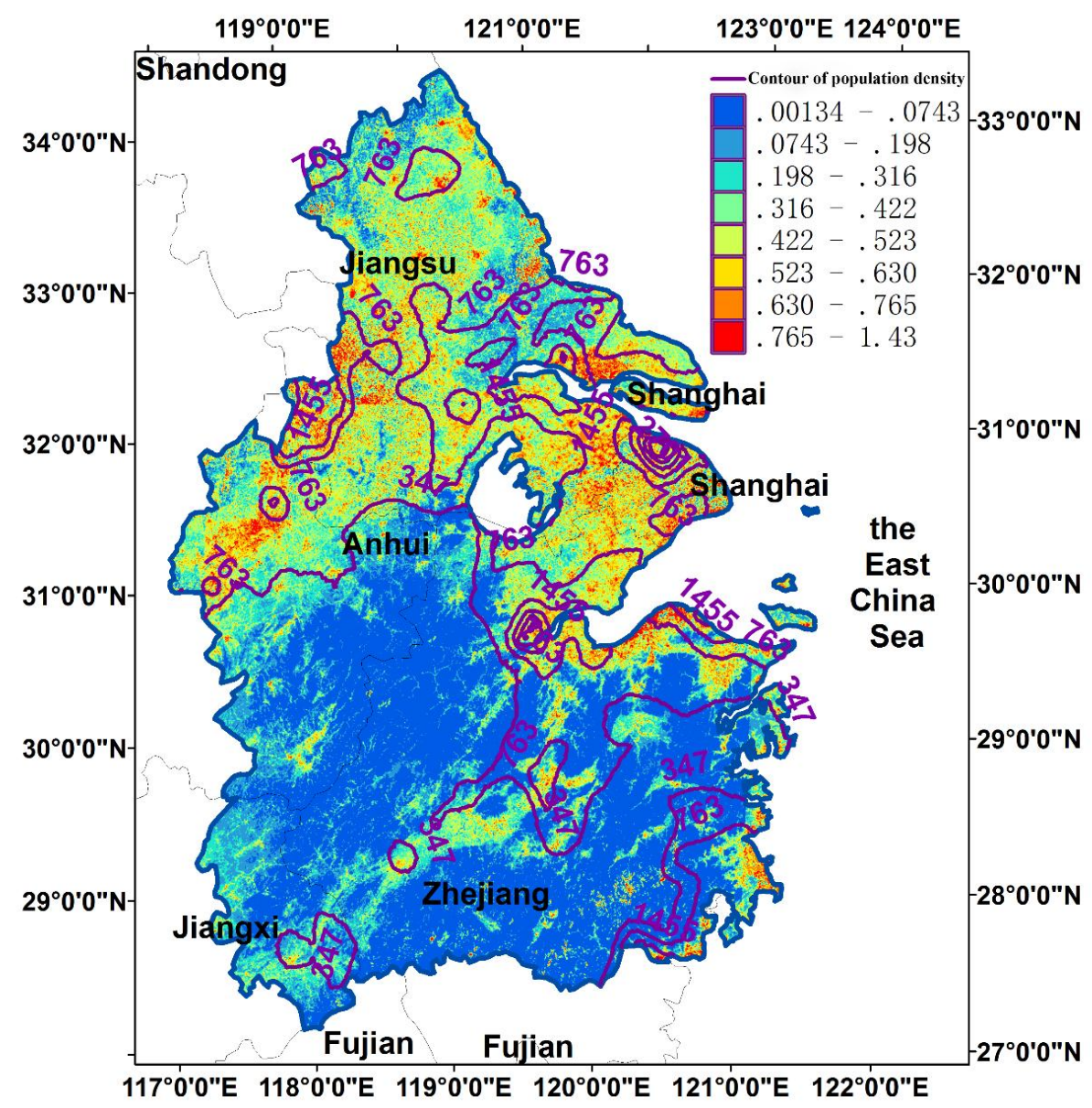

Figure 6. AOD with population contour

Overall, it can be drawn from the figure that distribution of AOD roughly conforms to the trend of population distribution. It means where the population density is high, AOD is high too, and vice versa. It also can be seen that in the district of high population region, such as Shanghai, southern Jiangsu and Qian Tang river region, the AOD value is higher too, which was expressed by a red color. In part of Zhejiang and Anhui, population density value is low and AOD value is smaller, which was expressed as a blue color. Meanwhile, intensive contour means that population density changes fast. In image above, we can find that AOD values change quickly in some concentric circles where contour is intensive. In the area where contour is sparse, such as most of the area in Zhejiang province, we can find that AOD value changing rate is smaller. This means that population density and aerosols have roughly similar distribution characteristics. 


\section{Discussion}

In the selected research area, we calculated average population density and aerosols in each counties and cities, respectively. Thus, we got 147 sets of values. After that, we calculated the natural logarithm of each group of population density value and AOD, respectively. The scatterplot was drawn with Napierian logarithm of AOD being taken as the abscissa and Napierian logarithm of population density being taken as the ordinate of each statistic group. The outcome was used to conduct trend analysis. The result is shown in Fig. 7.
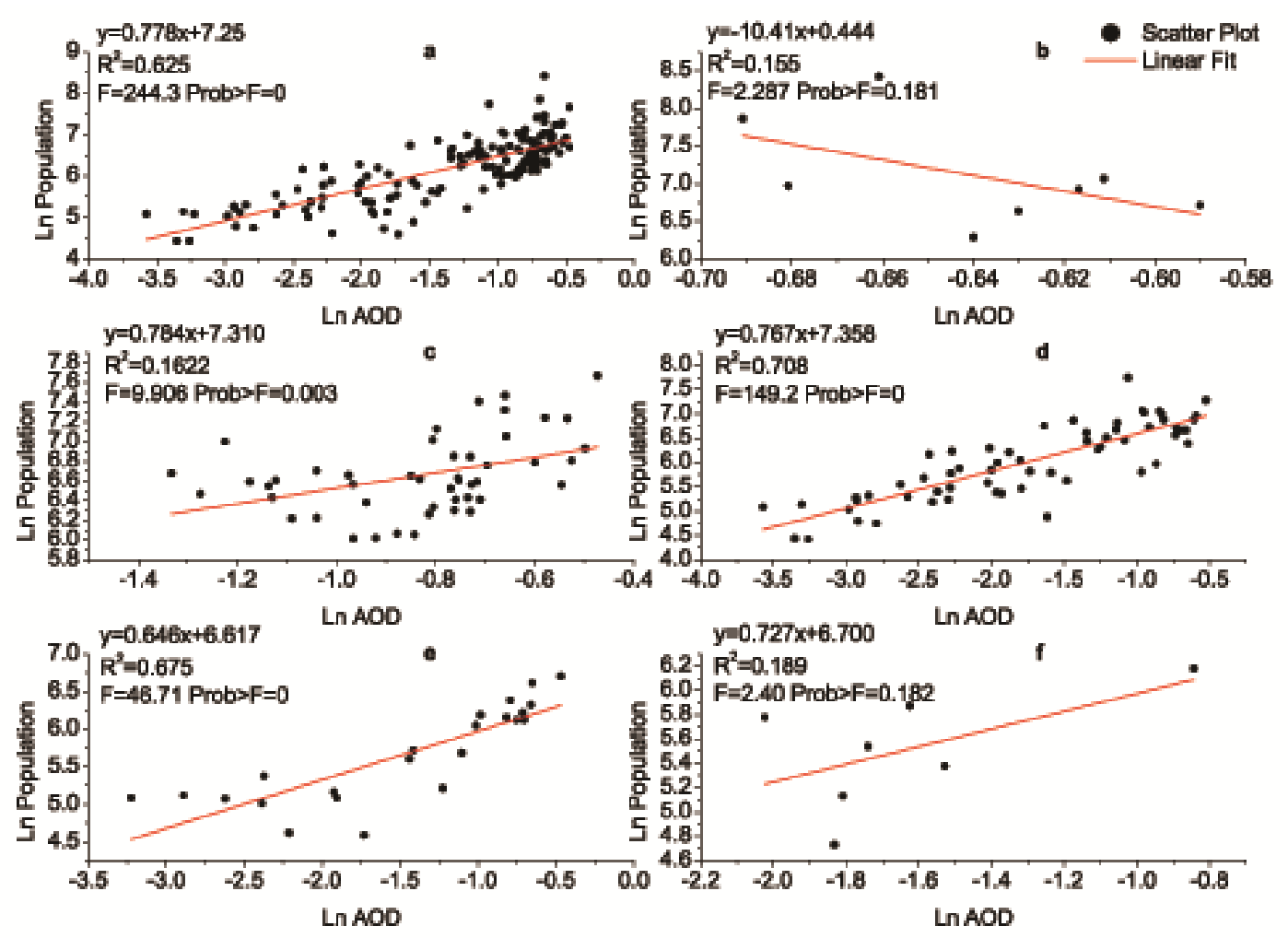

Figure 7. Scatter diagram of AOD and populations' natural logarithm (a represents the result in the whole research region, $b, c, d$, e, and f represent results in Shanghai, Jiangsu, Zhejiang, Anhui, and Jiangxi, respectively)

In the figure, abscissa point value is Napierian logarithm of aerosol; The y coordinate value is Napierian logarithm of population density values. The dotted line is a linear regression trend line, and the equation is the expression of the linear regression equation. It can be seen from the diagram that after calculating the natural logarithms of AOD and population density values, they confirm the linear correlation, showing that the two factors confirm correlation well and meet the equation:

$$
\mathrm{A}=\mathrm{CP}^{\beta}
$$


In the expression, $A$ refers to the $A O D$ value, $C$ and $\beta$ are coefficients, $P$ refers to the population density. According to the expressions of the linear regression equation, it can be obtained that $\mathrm{C}=8.935^{*} 10^{-}$and $\beta=1.286$ in the research region. The $\mathrm{F}$ test value is 244.3 , bigger than $\mathrm{F}_{0.05}(1,145)$, showing that the fitting result is reliable. Figure 7 (b-f) is the scatterplot for the points by province. Its order is Shanghai, Jiangsu, Zhejiang, Anhui, and Shanxi. Table 3 shows $\mathrm{C}$ and $\beta$ value for the different provinces.

Table 3. The value of $C$, $\beta$, squared correlations $F$-test value and confidence of the equation about population density and $A O D$

\begin{tabular}{c|c|c|c|c|c|c}
\hline Province & Counties or cities & C value & $\boldsymbol{\beta}$ value & $\mathbf{R}^{\mathbf{2}}$ & F test & Prob>F \\
\hline Shanghai & 8 & 1.04 & -0.0960 & 0.155 & 2.287 & 0.181 \\
Jiangsu & 47 & $8.89 * 10^{-5}$ & 1.28 & 0.162 & 9.906 & 0.003 \\
Zhejiang & 62 & $6.81 * 10^{-5}$ & 1.30 & 0.708 & 149.2 & 0 \\
Anhui & 23 & $3.54 * 10^{-5}$ & 1.55 & 0.675 & 46.41 & 0 \\
Jiangxi & 7 & $9.91 * 10^{-5}$ & 1.38 & 0.189 & 2.400 & 0.182 \\
\hline
\end{tabular}

We can see from the graph that in addition to Shanghai, the relationship between population density and aerosol of the rest provinces still broadly fit the equation (1). Because Shanghai's points are too less, the correlation coefficient is low and the confidence is 0.181 . It means the two sets of data do not have a significant difference in Shanghai. Jiangxi shows the same results. Therefore, the regression equation is not representative, in the following discussion we will not refer to them. In addition to Shanghai, the rest of the provinces $\beta$ value is larger than 1 . From the table, we can also conclude that in Anhui, $\beta$ value is higher than that of Jiangsu and Zhejiang. This means the increased aerosol value of Anhui is bigger than that of Jiangsu and Zhejiang with each additional unit of the same population. Also, provinces have different $\mathrm{C}$ values. The highest $C$ value is in Jiangxi. Anhui's $C$ value is the lowest. This means that under the condition of invariable $\beta$, increase of AOD in Jiangxi is highest and that of Anhui is lowest. Nevertheless, due to the various $\beta$ of provinces, $C$ value is only a coefficient rather than an index, thus the impact of $\mathrm{C}$ value is limited.

We compared our results with publically available researches. Lamsal et al. (2013) studied the relationship between the population density and $\mathrm{NO}_{2}$ from a global scale. He obtained ground-level $\mathrm{NO}_{2}$ concentrations via satellite (OMI) and GEOS-Chem, and compared it with the population density of those regions. On the choice of the study region, he chose countries such as America, Europe, China and India. Compare to their research, we focus on east China area because we have a higher image resolution there. Their image resolution is $0.25^{\circ} \times 0.25^{\circ}$ while our resolution is up to $300 \mathrm{~m} \times 300 \mathrm{~m}$. This makes the regional internal comparison possible.

Through the research, they think ground-level $\mathrm{NO}_{2}$ concentration is exponentially 
related with population density ( $\mathrm{r}$ from 0.69 to 0.71 ) which is similar with the conclusion of ours. At the same time, in their research, the $\beta$ value of rapid industrial development area is higher and vice versa. The $\mathrm{NO}_{2}$ of urban areas grows faster than that of the rural areas. These conclusions is also pretty much similar to ours. However, in their study, $\beta$ is generally less than 1 , means that the increase of $\mathrm{NO}_{2}$ is lower with each additional unit of the population. Considering the source, flow direction, physical and chemical properties of $\mathrm{NO}_{2}$ and aerosol are different, it is possible to be in such situation, but it also means that the study of the relationship between population density and atmospheric pollutants remains to be study further and deeper.

\section{Conclusion}

According to the principle of the near IR-visible surface albedo correlation approach, this research takes HJ satellite remote sensing images with high spatial resolution combining with the cloud removal method, to retrieve the distribution of aerosol in east China economic-developed areas and analyzes the relationship between the aerosol distribution and population density. Conclusion is as follows:

The spatial resolution of AOD retrieved from HJ satellite image is higher than the MODIS results. The resolution of MOD04L2 aerosol products is $10 \mathrm{~km} * 10 \mathrm{~km}$ while that of our HJ satellite AOD is $300 \mathrm{~m}^{*} 300 \mathrm{~m}$ after resampling. The high-resolution AOD benefits us in focusing on smaller area. We are able to compare the AOD between cities or provinces rather than countries or continents. We could research more specific issues and raise more practical proposal with the advantage of our results.

There is a high correlation between AOD distribution and population density in the research region of east China. The population density value and the AOD was taken to numerical and linear regression equation fitting, the correlation coefficient is $R^{2}=0.625$ which indicates a high correlation. The slope of the fitting equation is positive, means that where the population density is high, AOD is large and vice versa. Population density is higher in Jiangsu and Shanghai. The AOD value is higher, too. It is reflected in that the average value is higher while the minimum value is higher too. In Anhui, Zhejiang and Jiangxi, the population density is lower and the average and the minimum value is lower too. After conducting linear regression of Napierian logarithm of population density and the $\mathrm{AOD}$, we get that the data fits $\mathrm{A}=\mathrm{CP}^{\beta}$. It suggests that each additional unit of the population brings the added value of the AOD increase. Research the relations between population and aerosol by provinces, the added value of the aerosol with per population increase of Zhejiang province is lower, the added value of the aerosol with per population increase of Jiangxi and Anhui is higher. As for the reason, there is vast low population region in Zhejiang province in the cause of mountain areas. Meanwhile, Jiangxi and Anhui is in the inland and air flow is small lead to the low AOD in those places.

In that way, we can say large cities face more aerosol pollution pressure caused by population. To most of the cities, the $\beta$ value is larger than 1 . When the population is 
increasing, the gathering speed of AOD is becoming larger. This means the aerosol increment of a city with large population is severer than that of a city with less population with each additional unit of same population. Also, cities have different $\mathrm{C}$ values. Nevertheless, due to the various $\beta$ of cities, $C$ value is only a coefficient rather than an index, thus the impact of $\mathrm{C}$ value is limited. To those cities which has the need for prevention and control aerosol pollution, if the population can't be controlled in a reasonable scope, then it will face greater aerosol pollution prevention pressure. Meanwhile, for some small cities or cities with less aerosol pollution prevent pressure, they also cannot treat it lightly. Due to the $\beta$ value is generally greater than 1 , the AOD will keep increasing though the population is not that large. If the population is not well controlled, aerosol concentration will be exponential increase. The more population is, the greater the prevention pressure of aerosol pollution will be.

Acknowledgements. This research was supported by the National Natural Science Foundation of China (Grant No.41001047).

\section{REFERENCES}

[1] Charlson, R. J., Schwartz, S., Hales, J., Cess, R. D., COAKLEY, j. J., Hansen, J. and Hofmann, D. (1992): Climate forcing by anthropogenic aerosols. - Science 255(5043): 423-430.

[2] Che, H., Xia, X., Zhu, J., Wang, H., Wang, Y., Sun, J., Zhang, X. and Shi, G. (2015): Aerosol optical properties under the condition of heavy haze over an urban site of Beijing, China. - Environmental Science and Pollution Research 22(2): 1043-1053.

[3] Deuzé, J., Bréon, F., Devaux, C., Goloub, P., Herman, M., Lafrance, B., Maignan, F., Marchand, A., Nadal, F. and Perry, G. (2001): Remote sensing of aerosols over land surfaces from POLDER-ADEOS-1 polarized measurements. - Journal of Geophysical Research: Atmospheres 106(D5): 4913-4926.

[4] Deuze, J., Goloub, P., Herman, M., Roger, B. and Tanre, D. (2003): Aerosol remote sensing from POLDER measurements. - Geoscience and Remote Sensing Symposium, 2003. IGARSS'03.

[5] Eck, T. F., Holben, B. N., Slutsker, I. and Setzer, A. (1998): Measurements of irradiance attenuation and estimation of aerosol single scattering albedo for biomass burning aerosols in Amazonia. - Journal of Geophysical Research: Atmospheres 103(D24): 31865-31878.

[6] Engel-Cox, J. A., Holloman, C. H., Coutant, B. W. and Hoff, R. M. (2004): Qualitative and quantitative evaluation of MODIS satellite sensor data for regional and urban scale air quality. - Atmospheric Environment 38(16): 2495-2509.

[7] Fang, L., Yu, T., Gu, X., Wang, S., Gao, J. and Liu, Q. (2013): Aerosol retrieval and atmospheric correction of HJ-1 CCD data over Beijing. - Journal of Remote Sensing 17(1): 151-164.

[8] Gunaseelan, I., Bhaskar, B. V. and Muthuchelian, K. (2014): The effect of aerosol optical depth on rainfall with reference to meteorology over metro cities in India. - Environmental Science and Pollution Research 21(13): 8188-8197.

[9] Kaufman, Y., Gitelson, A., Karnieli, A., Ganor, E., Fraser, R., Nakajima, T., Mattoo, S. and Holben, B. (1994): Size distribution and scattering phase function of aerosol particles retrieved from sky brightness measurements. - Journal of Geophysical Research: Atmospheres 99(D5): 10341-10356. 
[10] Kaufman, Y., Tanré, D., Gordon, H., Nakajima, T., Lenoble, J., Frouin, R., Grassl, H., Herman, B., King, M. and Teillet, P. (1997a): Passive remote sensing of tropospheric aerosol and atmospheric correction for the aerosol effect. - Journal of Geophysical Research: Atmospheres 102(D14): 16815-16830.

[11] Kaufman, Y., Wald, A., Lorraine, L., Gao, B., Li, R. and Flynn, L. (1997b): Remote sensing of aerosol over the continents with the aid of a $2.2 \mathrm{~m}$ channel. - IEEE Trans. Geosci. Remote Sensing 35: 1286-1298.

[12] Kaufman, Y. J. and Sendra, C. (1988): Algorithm for automatic atmospheric corrections to visible and near-IR satellite imagery. - International Journal of Remote Sensing 9(8): 1357-1381.

[13] Kaufman, Y. J., Wald, A. E., Remer, L. A., Gao, B.-C., Li, R.-R. and Flynn, L. (1997c): The MODIS 2.1- $\mu \mathrm{m}$ channel-correlation with visible reflectance for use in remote sensing of aerosol. - Geoscience and Remote Sensing, IEEE Transactions on 35(5): 1286-1298.

[14] King, M. D., Kaufman, Y. J., Tanre, D. and Nakajima, T. (1999): Remote sensing of tropospheric aerosols from space: Past, present, and future. - Bulletin of the American Meteorological Society 80(11): 2229-2259.

[15] Kokhanovsky, A., Breon, F.-M., Cacciari, A., Carboni, E., Diner, D., Di Nicolantonio, W., Grainger, R., Grey, W., Höller, R. and Lee, K.-H. (2007): Aerosol remote sensing over land: A comparison of satellite retrievals using different algorithms and instruments. Atmospheric Research 85(3): 372-394.

[16] Lamsal, L., Martin, R., Parrish, D. D. and Krotkov, N. A. (2013): Scaling relationship for NO2 pollution and urban population size: A satellite perspective. - Environmental science and technology 47(14): 7855-7861.

[17] Latha, K. M. and Badarinath, K. V. S. (2005): Factors influencing aerosol characteristics over urban environment.- Environmental Monitoring and Assessment 104(1-3): 269-280.

[18] Levy, R. C., Remer, L. A., Kleidman, R. G., Mattoo, S., Ichoku, C., Kahn, R. and Eck, T. F. (2010): Global evaluation of the Collection 5 MODIS dark-target aerosol products over land. - Atmospheric Chemistry and Physics 10(21): 10399-10420.

[19] Levy, R. C., Remer, L. A., Mattoo, S., Vermote, E. and Kaufman, Y. J. (2006): A new algorithm for retrieving aerosol properties over land from MODIS spectral reflectance.

[20] Liang, S., Zhong, B. and Fang, H. (2006): Improved estimation of aerosol optical depth from MODIS imagery over land surfaces. - Remote Sensing of Environment 104(4): 416-425.

[21] Lianou, M., Chalbot, M.-C., Kavouras, I., Kotronarou, A., Karakatsani, A., Analytis, A., Katsouyanni, K., Puustinen, A., Hameri, K., Vallius, M., Pekkanen, J., Meddings, C., Harrison, R., Ayres, J., ten Brick, H., Kos, G., Meliefste, K., de Hartog, J. and Hoek, G. (2011): Temporal variations of atmospheric aerosol in four European urban areas. Environmental Science and Pollution Research 18(7): 1202-1212.

[22] Ma, Z., Hu, X., Huang, L., Bi, J. and Liu, Y. (2014): Estimating ground-level PM2.5 in China using satellite remote sensing. - Environmental Science and Technology 48(13): 7436-7444.

[23] Martonchik, J. V., Diner, D. J., Crean, K. A. and Bull, M. A. (2002): Regional aerosol retrieval results from MISR. - Ieee Transactions on Geoscience and Remote Sensing 40(7): $1520-1531$.

[24] Oh, S.-N., Sohn, B.-J. and Lee, S.-S. (2004): Aerosol optical and radiative properties observed at Anmyeon and Jeju, Korea in the spring of 2000 and 2001. - Environmental monitoring and assessment 92(1-3): 95-115.

[25] Paredes-Miranda, G., Arnott, W. P., Moosmüller, H., Green, M. C. and Gyawali, M. (2013): Black Carbon Aerosol Concentration in Five Cities and Its Scaling with City Population. Bulletin of the American Meteorological Society 94(1): 41-50.

[26] Rosenfeld, D. and Woodley, W. L. (2000): Deep convective clouds with sustained 
supercooled liquid water down to-37.5 C. - Nature 405(6785): 440-442.

[27] Tanré, D., Deschamps, P., Devaux, C. and Herman, M. (1988): Estimation of Saharan aerosol optical thickness from blurring effects in Thematic Mapper data. - Journal of Geophysical Research: Atmospheres 93(D12): 15955-15964.

[28] Tanre, D., Holben, B. N. and Kaufman, Y. J. (1992): Atmospheric correction against algorithm for NOAA-AVHRR products: theory and application. - Geoscience and Remote Sensing, IEEE Transactions on 30(2): 231-248.

[29] Wang, X. and Wan, G. (2014): China's Urban Employment and Urbanization Rate: A Re-estimation. - China and World Economy 22(1): 30-44.

[30] Wolf, M. E. and Hidy, G. M. (1997): Aerosols and climate: Anthropogenic emissions and trends for 50 years. - Journal of Geophysical Research-Atmospheres 102(D10): 11113-11121. 